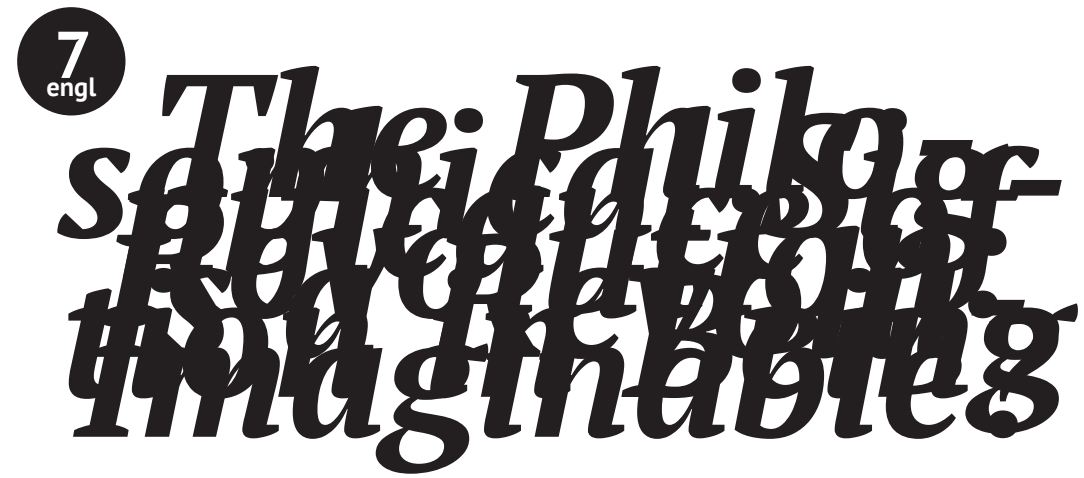

\title{
The Philosophical Significance of Revolution: Is a Revolution in Being Imaginable?
}

Based on the discussion that took place on November 7, 2018 in European University at St. Petersburg

Artemy Magun, Alexander Pogrebniak, Yoel Regev, Oxana Timofeeva, Marina Simakova, Anton Syutkin

\section{Discussion}

Artemy Magun: We are gathered here today to discuss the philosophical results of the past anniversary, in 2017, of the Russian Revolution. Much that is true has been said about the gains of this revolution, about the causes of its defeat, about its significance in the current stage, where revolutions and revolutionary movements are continuing but speak either only in the good old language of nationalism or in the new language of postcolonialism, of the precariat, of queerness and so on. Today we will be discussing an aspect that, if anything, took second place in this battle of intellects: what, based on the results of its history, the program of the Russian Revolution actually was, what its ontological and universally historical - if not cosmic - significance is, as well as the significance of the general revolutionary form that the Great October Revolution helped secure as a political form of the present era. In this case, the program was Marxist communism and Leninist socialism, but the majority of us do not believe that this program needs to be reproduced literally today. Rather, ethical and ontological reflection is necessary here as regards the program, the perturbations of its implementation in the USSR, and its theoretical armor. 
Of course, discussion of the revolution inside Russia has taken on a distinct tone. A negative assessment of the Revolution of 1917 has prevailed here thus far, and there is an explanation for that. First, there is still no real distance toward the events that in reality led to a tremendous quantity of victims and suffering. Second, in Russia we are wedged between conservative and ultraliberal ideologies, and they both oppose revolution - or at any rate the revolution of 1917. For a time, the Revolution of 1917 made Russia a vector of development for the progressive community in the rest of the world. From within, however, it did not seem as such. The scale of moral and physical catastrophe was commensurate with its avowedly cosmic ambitions. For others, socialism was awe-inspiring; for itself, socialism had become abhorrent. This is why, having united Russia with the world in the twentieth century, the revolution continues to divide us today; in this connection it is doubly important to discuss the revolution and its consequences at the theoretical and international levels.

What is the philosophical significance of the revolution of 1917 ? What did this revolution change in our understanding of existence? Was it a philosophical revolution, a revolution in the understanding of the world, or even a revolution in existence? Which changes occurred in our perception of history, in the conception of the structure of society and the state? Did this revolution become "intellectual," or was it solely social and political? Did it leave behind any eternal theoretical heritage? We will be talking about all this today with teachers and graduate students of the Social and Political Philosophy program at the European University at St. Petersburg.

Oxana Timofeeva: In responding to the questions posed, I would like to state my own theory of five revolutions that can be imagined as a series of concentric circles. The innermost, and smallest, circle is a revolution in one country. You know that in 1926, starting with the Fourteenth Congress of the VKP(b) and after the defeat of the idea of world revolution, when revolutions were collapsing in the West, in the advanced capitalist countries of Europe, the theory of socialism in one country became the official ruling doctrine in the USSR. With that, the Marxist idea that the revolution had to begin precisely in advanced capitalist countries suffered its downfall. This conversion into the concept of socialism in one country was conditioned on the one hand by economic backwardness, and on the other by the capitalist environment in which Russia found itself after the revolution. Lenin's position on this point was an ambivalent one: he believed that it was stupid to sit twiddling your thumbs and waiting until the very events Marx had predicted became true in the West: it was necessary to take advantage of a revolutionary situation and to take power when it fell into your hands. In his opinion, however, the revolu- 


\section{Discussion}

tion had to move further, and it had to continue in the countries of the West no matter what. In the modern world, China retains its formal status as a socialist commonwealth, separate and even isolated. We are faced with an entire range of problems with a revolution of this kind and with the socialism of a revolutionary state of this kind. When the question of radical social change is posed in intellectual, cultural or artistic microsocieties, the discussion often focuses on certain autonomous zones or islands where it will finally be possible to establish the kingdom of freedom, separate from the entire world. In some ways, this is the Platonic state. Incidentally, long before Stalin - in 1878 - the concept of socialism in one country was promulgated by Georg von Vollmar, the president of the Bavarian section of the Social-Democratic Party of Germany. He believed that Germany was moving forward and succeeding in comparison with England, and that it could now build socialism.

The next largest circle in size, Revolution II, is the world revolution in the classical scheme of Marx and Engels. Engels's 1847 work, The Principles of Communism, was designed as a succession of questions and answers. Among the questions is this one: would it be possible for this revolution to take place in one country alone? Engels answered: no. By creating the world market, big industry has already brought all the peoples of the earth, and especially the civilized peoples, into such close relation with one another that none is independent of what happens to the others. In his opinion, the communist revolution would not be only a national one - it would take place simultaneously in all developed countries (that is, at least, in England, America, France and Germany).

For me, an interesting precursor to the concept of world revolution is Kant, who introduced the new figure of the cosmopolite, the world citizen. The idea of equality and of internationalism was already inherent in his anthropological pragmatics, so an interesting link results between Kant with his cosmopolitanism and Marx and Engels with their slogan, "Workers of the world, unite!" In Kant, however, the cosmopolitan man does not possess a concrete specialization; he is a universal man, not connected with production. By contrast, Marx's human being is defined by universal production, by labor. In the field of philosophical anthropology, the concept of world revolution raises the issue of the new man who succeeds the proletarian, and of what to do with the 'old' people, the bearers of reactionary bourgeois consciousness.

The next "revolutionary" circle is planetary revolution. Ecological problems, in conjunction with the ideas of the revolutionary vanguard, move to the fore here. This combination was important for our predecessors in both 1917 and the years that followed - say, for Platonov or Mayakovsky, who promulgated a new century of machines, turbines, and technology capable of transforming nature with its inertia, instincts, "natural" injustice, and inequality. At the same time, they believed that 
nature itself had to be liberated and, with the help of humanity, moved forward into a new epoch. Here, Platonov takes up with contemporary post-humanist utopias - for instance, Timothy Morton, who writes about solidarity with "nonhuman people" - and with various ideas about the liberation of nature and the search for revolutionary forces somewhere outside of and beyond the human. If the world revolution is a revolution of people and society, then the planetary revolution is a shift of the entire natural order - and its subject does not necessarily have to be a human.

The next circle is cosmic revolution. Here, of course, Russian cosmism comes to mind: Anton Vidokle's film, for example, on the Russian biophysicist Alexander Chizhevsky is called The Communist Revolution was Caused by the Sun. The sun is at the center not only of mythology and traditional cosmogony, but also of the most contemporary philosophical inquiries. Lyotard, for instance, discussed what humanity would do when the sun burns out and the end of the world draws near. And Reza Negarestani, who called oil "the black corpse of the sun," notes the contrast between a masculine order linked to the idolization of solar energy and the impending chthonic forces bursting forth from under the earth. There is an opposition between sky and earth here, between what comes out from under it and threatens catastrophes. The task of the cosmic revolution becomes the alternation not only of the earth and the natural order, but of the entire cosmos.

And, finally, the fifth circle is the ontological revolution. Can we change the order of being itself, tamper with it - and if so, then is something wrong with being itself? And more importantly, what are "we"? The way in which we can change the order of being depends on this answer. For me, questions of ontology and revolution refer to Hegel, to his understanding of the French Revolution, and also to the possibilities of continuing this understanding. For example, Lunacharsky wrote that we have to cast off all the "bourgeoisness" of Hegel and adopt what was most important in him: the foundations for the dictatorship of the proletariat available in his philosophy. These foundations, of course, are difficult to ascertain and counterintuitive. Important changes took place in philosophy in the period between the French and the socialist revolutions: a certain ontological horizon, linked with the concept of "we," was introduced - the element of collectivity. In the twentieth century, authors such as Jean-Luc Nancy set about to reinterpret it. By clearing the ontological horizon for communism, Nancy promulgates the primacy of multiplicity in the order of existence - a multiplicity that lies at the foundation of creation. Of course, this is not the only hypothesis; many different concepts of "we" exist, and it is in collective activity in particular that, in my opinion, the answers to the question of ontological revolution and the boundaries of its possibilities should be sought. 


\section{Discussion}

Yoel Regev: I think I ought to begin with what Oxana finished on. To solve the problems linked with the revolution of 1917, we have to consider the possibility of producing changes in existence, in ordering the existent and the nonexistent. The main problem of the revolution of 1917 is an ontoeconomic one: in other words, the problem of the preliminary investment of desire in a specific form of existence as the main and decisive one. This form consists of the primacy of the givenness of the ungiven, or of the immanent impossible, which functions as a kind of supraexistence (that is, existing first and foremost, and preferably defining and ordering the degrees of existence). Whatever is involved with it to a greater degree, exists to a greater degree. Whatever is involved with it to a lesser degree, exists to a lesser degree. I believe that the problem of the revolution of 1917 consisted in the fact that the materialistic dialectic, which the theoreticians and practitioners of the social-democratic movement drew upon, was insufficiently materialistic. This can be formulated somewhat differently: the revolution was a rupture and was successful because it drew upon the dialectic, and its inadequacy and dead ends are explained by the fact that the dialectic was still idealistic and consequently based on the primacy of the givenness of the ungiven (the immanent impossible), which in Hegel concretely assumes the form of the dialectic of being and nothingness. The entire dialectical chain in his Science of Logic begins with this. Now, I will attempt to briefly illustrate what I've said. As part of this approach, a certain situation will be considered as initially existing: one in which we simultaneously exist and do not exist, in which we hold in our hands a paradoxical object endowed with the property of simultaneously being and not being, or we ourselves become such an object. The essence of this object consists in escaping our clutches. I think that this is one of the main problems of the contemporary situation, and for some reason we are not aware of it. Philosophers - like Heidegger, for example - paid attention to it, however. He asked himself "what is existence?" and said that existence is an eluding - that is, when something is given precisely as an ungiven. In fact, this style of thinking is intrinsic not only to Heidegger, but to every contemporary philosopher, and this is the essence of capitalism. As Marx wrote, every ideology makes absolutes, ripping what relates to a specific historical context out of that historical context. For us now, being means not being; being means finding ourselves in a situation where something eludes us, and with the fixing this situation of the givenness of the ungiven precisely as given and elusive. The fact that the revolution of 1917 assumed the primacy of the givenness of the ungiven finds its expression in a sequence of philosophical and political problems - the problem of spontaneity and organization, for example; one of the main problems of the revolutionary movement, beginning with Lenin's What is to be Done? and concluding with his argument with Rosa Luxemburg. This is a dialectical problem; it represents the oscillation between two poles: the absence of a state of being 
organized on the one hand, and the existence of said state on the other. The historical logic here consists in the fact that these two poles are temporally linked, following one another. Initially we are somewhat organized, then somewhat spontaneous, then again somewhat organized, then again somewhat spontaneous; the truth expressed here is the truth of the unity of organization and spontaneity as one of the manifestations of the givenness of the ungiven. Or, for example, the problem of a revolution in one country - a certain fluctuation between the territorial organization of the revolution and the absence of its confinement. Oxana pointed out that Lenin thought in a similar manner, now writing about one, then writing about the other. This is also a kind of diachronic unfolding of a fundamental contradiction that ultimately leads neither to an actual contraction nor to an actual broadening of the revolution becoming impossible. I believe that the revolution can come to fruition only as a revolution in one monad. On the other hand, if it comes to fruition precisely as a revolution in one monad (I will explain this later), then it can have a truly universal scale and be a cosmic revolution.

The last example is the problem of the gulags, the problem of the 1930s and 1940s. Here, in my opinion, the power of the immanent impossible, or the givenness of the ungiven, comes to fruition as the givenness of the unendurable, as a certain affect that is found at the boundary of our ability to endure it (here, the sublime in Kant comes to mind). Nonetheless, this affect does not fully destroy our ability, but when this destruction takes place we can formalize it. I believe that a more comprehensive theory of the unendurable is necessary here, as the subject of the investment of desire. In post-Soviet space, the problem of the gulags appears as the main issue of the revolution, and every liberal criticism is founded upon this. Without a doubt, this problem needs to be resolved somehow. You can appeal as much as you like to the solution proposed in the 1960s: things went wrong under Stalin because Stalin was a tyrant. That is as may be, but this response is obviously insufficient. It could be said that things went wrong under Lenin because the workers' state was replaced by a bureaucratic apparatus. In this sense, Deleuze and Guattari quite correctly write that with regard to the Russian Revolution, it is useless to pose the question of when exactly things went wrong, as ultimately it turns out that everything up to that point did not go as well as it could have. This is also linked to my thesis that there is a certain ontoeconomic problem here, that ordering the existent and the nonexistent is intrinsically problematic. The gulag system represented the unity of two different logics, not necessarily connected to one another. On the one hand, the logic of correction, and specifically the gulag as a corrective labor institution. As quickly became evident, however, correction through the use of labor turned out to be the mask for unendurable privation. It was correction through the use of contact with an unen- 


\section{Discussion}

durable affect, with unendurable suffering. Ultimately, correction was fully swallowed up by suffering.

In sum, I have depicted the engine of the manic-depressive unity of the givenness of the ungiven. But I think that there was a dialectic in the revolution, and it is linked with a second practical aspect. The question of the revolution is in fact the question of manipulation using essences - for example, on the disposal of the essence of Lenin himself, as in Voznesensky's famous poem I am in Shushenskoye. In the poem, Lenin appears as a wandering principle, settling now in Andrei Rublev, then in Stenka Razin, then in Vladimir Ulyanov, and in the future appearing before "dumbfounded Martians." It seems to me that this is close to Althusser's understanding of the Leninist theory of the weak link as a kind of manipulation - true, the essence here is not so much Lenin as it is the revolution itself. There are levels not connected to one another; there are laws not connected to one another, according to which they develop; but with that said, there is a moment in which unity becomes possible: a chance of inculcating a revolutionary character into the laws themselves emerges. I think that what is important in the revolution of 1917 is that it provided a chance of going beyond the logic of the givenness of the ungiven or the immanent impossible. This science of manipulation using essences allows us to pose the question of correction more broadly, tearing it out of the form of correction through unendurable affect. And that returns us to the ontological question of the correction of existence.

Alexander Pogrebniak: Could it be said that Lenin was just such an ontological operator, who put the dialectic onto the material plan and changed the formulation "the actual is not given" to "the actual is given, and the ungiven is not given," effectively returning ontology to Parmenides?

Yoel Regev: Not quite. In my opinion, Deleuze and Guattari have already sufficiently treated the thesis that the problem of capitalism and a non-materialist dialectic lies in the fact that separation does not help in solving the problem of the givenness of the ungiven, because the givenness of the ungiven is endowed with a kind of tension, an intensiveness. For this very reason it is impossible to overcome it by simply separating the given and the ungiven into different poles.

Alexander Pogrebniak: This is not about separating them into different poles. If we say that the ungiven is not given, we are not generally assigning it to some kind of pole - we are taking it as a whole (that is, this formula of zeroing out the problem of the givenness of the ungiven). 
Yoel Regev: But then the drive disappears. I think the main problem - and Nick Land, Deleuze and Guattari acknowledge this - consists in the fact that this completely absurd structure of the givenness of the ungiven somehow turns out to be attractive. There's something in it that holds people back. Boltanski and Chiapello speak about capitalism in a similar manner, as a completely absurd system: it is now generally not advantageous for anyone, everything in it is always bad, even for the exploiters. It could be supposed that some kind of attractor, an active substance, is contained within it. But what, from Althusser's point of view, is Lenin actually doing when - drawing on the theory of the weakest link - he actualizes the revolution? He also holds together different levels that are in no way related to each other. The political situation after the First World War, the development of capitalism in Russia, and the Russian national liberation movement are in no way linked to each other. Finding the weakest link means holding together those levels that have no links whatsoever between them, which by no means signifies holding the given and the ungiven together. Each of these levels is fully given; they are just not linked with one another, they are isolated. It is necessary to simply point out that the givenness of the ungiven is merely one of the means of holding together what is divided, whereas there may be many alternate means.

Artemy Magun: I have two questions for Yoel regarding the gulag, where people there were offered a specific experience of "the real." According to him, by the Lacanian "Real" I mean a certain experience of nearness to Yoel's "ungiven" - or I would say, to the "My-Great" (in contrast to the "Great Other") - and the futile attempt to hold it back. In the language of Hegelianism, this "real" can be identified with the ontological ideal of the intensification of existence, except that the ideal transcends "reality" and creates leeway for humanity in relation to existence. Is the hysterical spiral about the "real" that has been pointed out not taking place today? You both talk about a planetary revolution and about an ontological revolution as the maximum development of a political revolution. But the world revolution is not taking place today; every political revolution becomes bogged down and does not continue. Is a vast emptiness not arising on the grounds of the ideal? A revolution of this kind uncovers a gigantic foundation pit of melancholy into which we are all disappearing. If we understand revolution as the economy of the real and of its absence, "de-realization," then perhaps we need to discard both the one and the other and in their place construct some kind of other reality? Otherwise (that is, if the real is accessible to us only in the form of the tortures of the gulag or as an enemy attack during war), the situation appears dismal. Organizing rhythmic structures of real transcendence in politics has failed, as has embodying the energy of the "Really Great" without it relying on brutality: thus far we are rushing about be- 


\section{Discussion}

tween the sublime asceticism of testing ourselves (from yoga to the gulag) and the masturbatory hedonism of consumption.

Yoel Regev: In my view, the problem consists in the fact that we always find ourselves faced with an alternative: either retaining poles in the form of the intolerableness of reality or the liberal rejection of any tension in the separation of the poles, in the liberation of these retained extremes. I think that we really ought to return to Kant, having however grasped him from within. Kant is the very telegraph and mail that must be seized, as Russian revolutionaries wrote. Incidentally, Deleuze and Guattari understood this well when they said that the fundamental question is one of synthesis. Where is Kant's concept of the Copernican revolution? As Nietzsche would have expressed it, there is a tremendous noise - what opens up before us is the orbit of the heavenly bodies. And what these bodies in fact determine is the movement of the soil under our feet, which we do not perceive. So it is with the givenness of the ungiven, with unendurable suffering or unendurable delight. They alternate: in the 1930s, Jünger wrote essays on pain, and in general that decade was a time of unendurable power in the form of suffering and pain. In the 1960s, a shift to the opposite pole occurred: various theories of unendurable delight appeared (in Lacan, for example), as did practitioners of a kind of sexual revolution and so on. Both faded away sometime in the early 1990s, and they are definitely fading away at the present moment. It is precisely these mechanisms that define the 'orbit of the bodies,' this imperceptible movement of the soil under our feet on which everything depends, that Kant calls the mechanism of synthesis. They are responsible for holding our world together, and above all for holding together the sensuous and the rational. These are two levels that ought to fall to pieces, but they are nevertheless linked. I want to say that here it is necessary to not simply reject the power of the "unreal real" or of the unendurable; it is necessary to dispose of that pin, or that active substance, that binds us to it. My main assertion consists of the fact that this active substance is the fact itself of holding what is separate together, and that it does not follow that this holding together must be carried out precisely in the form of holding together the given and the ungiven. A multiplicity of forms exist in which it can be held together.

Artemy Magun: What is synthesis? It seems to me that in Hegel it is structured integration, the unity of form and content, but - for example - among dialectical materialists it most often appears that synthesis is simply the combination of opposing elements. And though it's not close to you, I suspect it is actually possible to imagine a society where, on the one hand, people live a capitalist and consumerist life, going to the theatre and the cinema, but the revolution takes place on Sundays. 
Yoel Regev: When I watched Westworld, I thought about it being possible to come out with a Russian analog to the amusement park shown there, in which people end up in the Wild West. If there were such a park in Russia, it would be 1917.

Artemy Magun: There could be several different parks, like in the series, and you could unexpectedly switch between one and another. There could also possibly be gulags there, where you could either be a prison guard or a prisoner. What was the mistake of revolutionaries in general, including the revolutionaries of 1917? To start with, the anarchistic element in them was too strong, and they did not understand the function of power itself in a revolution. At that stage, it seemed to them that the workers, tired of despotism, would somehow convene the Soviets and discuss everything, and their delegates could govern the country according to technological instructions. Later, when this didn't succeed, the revolutionaries swung to the other extreme: they themselves built a despotic regime and forgot about the revolution. They did not study the dialectic according to Hegel (though Lenin read him), and this dialectical moment was not theoretically worked out among them. If the ideal of a revolutionary state in which there had been a system of normalized power had existed among the revolutionaries from the very start, and at the same time democracy had been realized in a non-parliamentary fashion and a kind of ritualization had accompanied everything as well, then something probably would have succeeded with them.

Yoel Regev: That variant, however, preserves the separation of poles and their diachronic alternation. This model is worth getting rid of. I imagine another means of synthesis. Let's assume that Trotsky is still there alongside Lenin, and they're fighting to be realized in me, but they're incompatible with each other. I can decide that today I'll allow Lenin to be realized, and Trotsky tomorrow, but it's possible to act otherwise. It's possible to make it so that, having ended up inside me, they "enter into negotiations," as Latour calls it. This kind of micropolitics of "negotiations" could become the basis for global macroformations. It constitutes a praxis that is concerned with imposing itself on us, cracking and splitting it, and in this sense it is a continuation of Leninist politics. In my opinion, this is closer to Deleuze's and Guattari's concept of schizoanalysis, at least in one of its possible interpretations.

Alexander Pogrebniak: For all that, what is the logic of this synthesis? If Deleuze's concept is the disjunctive synthesis as synthesis through the greatest difference, is it so in this case? In other words, is it possible to synthesize not only Lenin and Trotsky, but in principle different personalities? So, for example, the rules of synthesis are spelled out in Kant, but everything is not synthesized with everything there because there are 


\section{Discussion}

strict limitations. What happens in this case? What could the logic of a Leninist or materialist synthesis consist of?

Yoel Regev: We do not choose what is to be synthesized, because there are always lines that are imposing themselves. We can ascertain what precisely is imposing itself on us, penetrating from different sides and being active in various media - that is, we can uncover these lines and how they repeat themselves. And this uncovering includes the moment of "clarification," of splitting off and discarding the superfluous. Having ascertained all this, we are given the opportunity to cut, to separate and to unite, using them in various ways, but we do not invent the "essence" itself, or lines.

Marina Simakova: I would like to return to the question of the philosophical significance of the revolution and the significance of the anniversary. The poem of Mayakovsky dedicated to the anniversary of the October Revolution, in which the anniversary took shape as a "repair en route." Mayakovsky's pathos lies in the fact that it was necessary to set the resolution of pressing tasks against empty commemorative holidays and festivities. But, if we look at this from the other side, Mayakovsky's poem proves to be prophetic: a hundred years later, we are occupied not so much with a holiday as we are with endless repairs. The subject is being repaired over and over again, history is being repaired, the revolutionary Marxist tradition is being repaired (but not renewed!). This fixation on the status of the breakdown, which is constantly perceived as a problem requiring repairs, appears to me in turn as problematic. Perhaps everything is the other way round, and the source of a new political passion and a political inspiration can be found in the breakdown itself, having ceased to occupy ourselves with faults and lacing splits together. Turning to the philosophical significance of the revolution, two things are worth mentioning. First, about the revolution as the abolition of law - and by law in this case I mean the legal system, norms, and, more importantly, the "objective laws of history." As Gramsci wrote, the October Revolution was "the revolution against 'Capital" - in the sense that those historical laws and calculations described by Marx and which lie at the foundations of Marxist orthodoxy did not work. The revolution did not take place in England, the country of highly advanced capitalism, nor in Germany, the country that had the strongest Social-Democratic movement at the time, but in Russia. In speaking of the Russian Revolution, we are dealing on the one hand with the abolition of law as norms and as rights, and on the other with the abolition of those laws in accordance with which developments were strictly determined - that is, laws that set history as some kind of objective force against concrete historical circumstances. The revolutionary moment is a moment when all these laws demonstra- 
bly lose their meaning, and that is why it is emancipatory. As regards the second aspect of the philosophical significance of the revolution, it consists of the collapse of the subject - the same one we are desperately trying to find, reconstruct, and repair today. The question of who can become a revolutionary subject, or what kind of subjectivity is capable of forcing a change in the social order, remains one of the sharpest of our time. Turning to the philosophical significance of the revolution, however, the following paradox can be noted: the question of a subject that can in some way be determined and defined has lost all meaning directly within the revolutionary moment. The event of the Russian Revolution reveals the presence of a collective will, and it is precisely in this that every revolution differs from the seizure of power and from an insurrection. What is the nature of the revolutionary subject, as the subject of mass aspirations and a mass movement? It was the working class, and poor peasants, and women sick of the war and the shortage of bread people of different ages, generations and beliefs, including those who approached the task of revolution with caution. The revolution teaches us that the persistent question of the subject, inevitably sending us off to the necessity of belonging to something - but on the level of rhetoric, transpiring to be a question of identity - can be suspended. The lesson of the revolution lies in the fact that everyone can become whoever they like, discarding themselves and becoming everything together with everyone.

Alexander Pogrebniak: I really liked that Oxana introduced the problem of the ontological revolution, and I would like to turn to her. I would even say that the ontological revolution is not simply the largest circle encompassing the four previous ones, but a "circle of circles" in the sense, so to speak, that it penetrates all the other circles and problematizes the circular character of each of those circles. It also opens up all these circles and shows, as it were, their ontological inadequacy. This circle is the last in succession, but at the same time it is first because everything that is most important takes place specifically on the ontological level of revolution. It could be said that the civilization to which we belong has two dimensions: the dimension of revolution and the dimension of philosophy (possibly correlating to the dimension of content and the dimension of expression). In other words, nothing but philosophy and revolution exists in our lives. It is one and the same movement examined in two dimensions. What is the nature of this movement? It is symptomatic of twentieth-century philosophy that it does not just speculate about revolution, recalling first the great French Revolution, then the Russian Revolution, then May 1968. There is such a thematic examination of the problem of revolution, but along with this it seems there is a subject that by no means refers to any revolutions but is specifically an attempt 


\section{Discussion}

to exclude a philosophical examination at the level of the pre-predicative understanding of existence. Tentatively speaking, there is a level of predicativeness prevailing in the sciences. It does not underlie the social structure, in accordance with which it becomes an attempt to separate society off into different corners in a consistent manner: separating different groups in society and then establishing relations among these groups. Clearly, this attempt is ultimately doomed to failure. The figure of Kant is in fact very important here. The revolutionary character of Kant himself lies in the fact that he showed beautifully that there is a categorical synthesis of existing things, but when this synthesis is taken and applied to universal things, it gives rise to contradiction and bursts asunder. The way out proposed by Kant can face criticism on ideological foundations because it suggests switching from science to morality. But at the same time in Kant, as is known, behind morality lies freedom. When we say "free act" or "free thinking," we are explicitly synthesizing a certain phenomenon or a certain event, and with that a synthesis of this kind does not assume placing contemplation under a rational category. We are not schematizing the free act; it cannot be demonstrated, and in that sense it remains revolutionary. We are attempting to apply a fundamental category to the absolute, to subjectivity as such, to the world as such, to humanity as such - none of this works, and we understand that other means of synthesis must emerge. This logic is valid even for Marx. If a commodity or a value from a categorical determination of the concrete region of the existent becomes a determination of something universal, of human existence as such, then a contradiction arises. This contradiction lies in the fact that the subject itself turns into a species of commodity. Economists say: there are different resources, and one of them is labor. But labor is not simply some kind of species of thing in this world, but a universal determination of the human essence. Marx has a different category for referring to it that is ignored by all the economists: specifically, "labor power." A fundamental contradiction arises between labor power as a universal human determination and labor as an imaginary commercial category that, according to Marx, must lead to revolution. A universal logic is visible here, linked with the fact that endeavoring to place everything in accordance with certain categories does not work. In his 1899 work The Development of Capitalism in Russia, Lenin - as is known - attempted to increase the number of proletarians by all possible means, employing this category in both warranted and unwarranted ways. In the moment of revolution, another form of presentation emerges through the people themselves, what Lenin calls the "popular creativity of the masses." So the people take the stage - heterogeneous, linking all those who are in no way linked to one another but against all odds forming unity. What is this unity? It is not a predicative unity, but united with regard to every categorical determination. Even 
Plato introduced this insight on unity into philosophy in Parmenides, and this unity is not a categorical determination of things that exist. This subject was best described in Agamben's short essay "Special Being," in which he shows that in his own concept, the idea (eidos, species) represents not a specific predicate with its limitations but a universal space for discovering what exists, a form of existence in the literal sense of the word. The idea, Agamben writes, sets forth the type, but does not classify it. It's like in the film Battleship Potemkin, where on one of the title cards it says, "In those days, the city lived together with the rebels," and then it shows people standing on the Odessa steps, waving their hands, and sailors standing on the ships, waving too, rowboats and barges laden with provisions are flying about, and there is fraternization. All the categorical determinations are recorded as if they are present in the film from beginning to end. In the preceding scene, where the sailors are covered with a scrap of tarpaulin, and in the famous scene of the shooting on the Odessa steps as well, there is nothing but this pre-predicative unity - the universal connectedness of people with one another - exactly as it is placed under any higher-level, transcendental category whatsoever, which leads to the uprising. An existence of this kind, overlooked between attempts to grasp and obscure it - between the shooting or the covering of people with a tarpaulin - is the best symbol of the revolution. Again, it is a prepredicative synthesis - or pre-categorical unity - of this type that emerges in philosophy and is the root of the philosophical thinking that distinguishes philosophy from any positivist thinking. Revolution is actually a very energetic event, and what can further be done with it is incomprehensible; this is why reaction and the attempt to describe anew the unity that has formed, to embed it in some kind of network of categories, immediately arises. Today, we see that owing to the tremendous quantity of repressive measures, the revolutionary atmosphere of the 1980s and 1990s was subject to division and segmentation into separate structures with access codes assigned to them. It is specifically a reaction, but on a structured level it demonstrates that revolution nevertheless continues to come to fruition, only unconsciously. A typical reaction of fear before one's own desire is taking place here, before the memory that there was something splendid, but it has come to an end.

Artemy Magun: Considering that the revolution of the 1980s and 1990s was a revolution against a revolution (the revolution of 1917), a kind of duality was inherent in it. Here, I would like to recall the wellknown attempt by Badiou to universalize the philosophical concept of revolution. For him, the revolution of 1917 was important, all its costs notwithstanding, and the revolution of 1968 was monumentally important (though its costs were even greater), but with that said he proposed isolating the idea of revolution as an abstract concept and employing this concept everywhere, to the experiences of every generation. We had our 


\section{Discussion}

own kind of revolution in the 1990s; the current generation of thirtysomethings didn't have that, but instead had the protests of 2011-2013 which for this generation became the event - fully in the spirit of what Badiou describes. Routinization sets in shortly after the event, but there is a possibility of returning in thought to the moment of an event that was capable of injecting a living force into a routinized present. Lacan would have said that this is the moment of enjoyment, which in this case is realized through a living memory, not an abstract memory of events a century distant.

Alexander Pogrebniak: This event is also reinforced by fidelity. You don't just recall it; recalling is, so to speak, the passive part. You have to specifically keep fidelity to it.

Artemy Magun: Yes, what's still important here is that every event of revolution not only opens up the real as an ideal, but also performs an essentially negative movement that sets up time, placing blocks on the path back, at least temporarily blocking a reversal. In a revolutionary situation they always say, "Not one step back!" For this purpose, in the French Revolution, the king was executed. He soon returned, but it was already a king of a quite different type. It was no coincidence that contemporaries said that an actual restoration did not succeed in France because restoration amounted to a completely new regime. And the active, subjective moment of fidelity consists precisely of keeping to a one-sided ideal and not falling into a mythical past with its full reversibility of everything. In spite of this ethical task, however, the problem with the theory of existence lies in the fact that its abolition is in fact brought about in the form of history, so that the same event happens over and over again. This troubles me a great deal; in essence this is exactly what happened with the revolution. In wanting to create a theory of history, Badiou instead gave us a theory of the abolition of history. The multitude of events taking place today indicate that history in some sense has come to an end, and come to an end through the events having turned out to be built into the spatial horizon of the world. Something is constantly taking place, but you are never headed anywhere; time, it seems, is not moving in a circle, but it is as if it has come to a standstill, forming a kind of standing wave.

Alexander Pogrebniak: I would like to answer very briefly. A similar kind of criticism has come to my mind, but it seems to me that it is possible to enhance philosophy with operators that permit us to see history in particular here, and not events repeating themselves again and again. In my opinion, events do not simply occur behind us like some kind of unalterable essence we nostalgically refer to and encourage this event to 
repeat. However attractive this event was within itself, a failure of sorts nonetheless took place with it. And this failure points at something new, which it is possible to recognize empirically according to specific symptoms. In my opinion, it would even be possible here to introduce a new category, simultaneously ethical and affective: disgrace. It could be regarded as the analogue to what Guy Debord calls the spectacle. As is known, the word pozorishche (dishonor or disgrace - Trans.) in the Slavic languages signifies a pageant. And today, actually, after all this time separating us from the revolution, much looks exactly like a disgrace. This means that an event should not simply be repeated, it should be repeated with a kind of new and radical intensity, because something remained unfulfilled after this event - for example, the actions of the security services, since the institution of the police itself did not change despite the revolution. Following the same logic, Agamben writes that the National Socialist regime led to the concentration camps, but after the annihilation of that regime the camp itself turned into a biopolitical paradigm of modernity. This is a disgrace. They tell us, "We're sorry, this is a precautionary measure," and the camps are associated with hygiene, maintenance of the borders, a passport regime and so on. We intuitively guess, however, that even if all this is rationally justified, it should not be; it is a disgrace. All this can be compared with a situation where the space opened by the event itself proves in our eyes to be occupied by the very same forces that a revolution, it seems, ought to have abolished.

Artemy Magun: Yes, it's important to add here that when a revolution occurs, you are coordinating with a specific social ideal and realizing it. But the ideal is soon forgotten, nothing comes out of it, enemies are everywhere, and you begin putting up barbed wire. Fencing a space off with barbed wire looks like a disgrace in comparison with the ideal. The revolution kindles the kind of ideal in whose light the entire history of the twentieth and twenty-first century now looks like a disgrace, and now like human rights violations, genocide, or a humanitarian catastrophe. I think that theoreticians like Adorno and Horkheimer did not recognize that the melancholic map of modernity they drew was possible only in the light of the great ideals of the Enlightenment and the October Revolution. The history of revolution is largely the history of the dialectic of the ideal.

Yoel Regev: In my opinion, the abstraction itself is somewhat problematic here. In general, what is intensity in Badiou becomes the main determining event, linked with the problem of his Maoism in general and with his rejection of economics in particular. This nuance is characteristic of all current left radical thought: of Badiou, Žižek, and others. The event, or the symptom, proves to be detached from reality. In fact, the way out 


\section{Discussion}

occurs beyond the boundaries of any kind of traditional determination; new subjectivity and intensity are created. But with that said, I think it important that it is created owing to some kind of concrete operation, that a concrete unity is formed: in Lenin's case, it is the union of the working class with the peasantry. Unity, as the fusion of essences that were previously not fused to each other, creates intensity. When we speak about this intensity as the way out beyond the boundaries of subjectivity, it is as if we are making a speech from far away, or - as Deleuze describes it - we are practicing "oblique looking." Nonetheless, we are within a specific situation and are looking from its perspective when we negatively describe what resists it as overly intensive (that is, surpassing the possible boundaries of experience in this situation) or non-subjective. In truth, however, there are concrete mechanics there.

Alexander Pogrebniak: But we cannot see or identify those mechanics if we don't have the abstract principle of switching from a division of categories already stabilized through contradiction to a situation where these limits are burst, and that is why we have to define them anew.

Yoel Regev: I'm not saying that this principle isn't needed altogether: it can play the role of some kind of propaedeutic. It is perhaps necessary in order to usher us into a specific field, but we don't need to remain in that field.

Anton Syutkin: In turn, I would like to come out with a certain criticism of ontologizing the revolution. It is obvious that in the ritual remembrances of 1917 and of communism there is a current moment that consists of the following: left, radical, and liberation politics over the last few decades have largely reduced themselves to democratic politics, but at that still distinguished from parliamentary, representative, and liberal politics. Mass movements of the Occupy Wall Street type are the paradigm of this history. There is a theory from Negri that describes this paradigm, as well as a number of other theories. In principle, the phenomenon itself of the masses, or the collective will, existing within the representative democratic system can be called an event, a kind of singularity, or even the abolition of law. But this is a flare-up that later vanishes; it plays out, and the question arises among everyone: why did it happen this way? The authors mentioned - Badiou, Žižek, Jodi Dean, Bruno Bosteels and many others - speak to the problem of organization and the political subject. But why is this organization necessary? It is necessary in order to complete the switch from a state of singularity, from an event, from a democratic revolutionary flare-up within the liberal representative order to an order where this event itself plays the main role. In other words, from a law - and even the undermining of this 
law - to a situation in which the absence of law becomes the law itself. That is, if we return to the idea of communism (Badiou nonetheless writes not so much about the idea of revolution as about the idea of communism, though there is also the ideal model of a revolution in his work), it lies in the fact that a system exists that in and of itself is not subject to external laws. For Badiou, it is the tribal multitudes, or non-categorical unity, arising as a result of an event. The ontological sense of revolution and communism lies in the fact that the idea of a classless society exists in philosophy, the same idea of a non-predicative existence. Obvious problems with ontologizing politics arise here, however. Heidegger committed a political blunder for which he is criticized today, specifically because he confuses ontological politics, or metapolitics, with politics as such. Another example: the link between the Hegelian dialectic and Leninist, or simply Soviet, politics. So Lukács and Lifshitz, in attempting to unify the Hegelian dialectic and Leninism, arrived at the conclusion that Thermidor was an inevitable stage in the development of the revolution, a certain stage that the abstract idea passes through, acquiring concreteness by means of suffering. As a result, they are compelled to admit a certain ontological legitimacy of Stalinism in practice, and consequently, by implication, the Stalinist terror. To some extent they turn out to be more Stalinist than Stalin himself, because in Thermidor they see the rational continuation of Leninist politics, and in Stalin, an eclectic incapable of comprehending the heights of the dialectical method. As regards Badiou, for him the problem of the catastrophic consequences of confusing metapolitics with politics is resolved through assuming politics to be an autonomous condition of philosophy itself. In understanding all the narrowness of a development of this kind that could eventually lead us to a transcendentalist position, it seems a certain autonomy of politics from the ontological perspective should be preserved. Of course, the ontological perspective is now important because the contemporary situation requires the re-invention of a regulative communist ideal, but a certain amount of skepticism nonetheless needs to be kept as regards this perspective.

Oxana Timofeeva: I would like to add something regarding the Hegelian Thermidor. I will bring together two moments important to me that were set forward earlier: revolution abolishes law on the one hand, and mobilizes the people on the other. The people as such are a pre-predicative unity - I like that definition - once it is actualized in the moment of revolution. Outside the events of a revolution, a unity of this kind does not exist. This is because in general there is no 'the people'; the Russian people, the French people, and so on, is a fictitious formation. But there are the people who went out into the streets in the revolutionary moment - these are the people Agamben speaks about as the oppressed. At 


\section{Discussion}

some moment we all emerge, mobilize, and acquire a "people's" life in that event that, it is true, quickly comes to an end. It is a phenomenon of the kind that flares up and cannot last in the same quality, as the people. In turn, the abolition of law described by various authors is linked with the dictatorship of the proletariat, and with revolutionary dictatorship in general. Hegel wrote about it when he proved the necessity of Thermidor and the terror. Terror, like Angst, is linked with absolute freedom. The subject of this freedom is consciousness, which travelled a specific path and at a specific moment remained in complete solitude. It destroyed the entire world, and above all the law (of this old world). The difference between Kant and Hegel here is interesting. As is known, Kant did not quite welcome the revolution - especially the execution of the king, because his beheading was a demonstration of the abolition of law, which according to Kant was a terrible evil. There must be a guarantee in law, and this guarantee was the monarch; if the guarantee itself is destroyed, then no law is possible. In Hegel, this schema becomes unnecessary. He described a situation where heads were flying like heads of cabbage, and it could be said that a diagnosis of the given state is closest to psychosis. In his book Subjectivity and Otherness, Lorenzo Chiesa writes that psychosis abolishes the figure of the father and the figure of law: the psychotic turns out to be alone with the real; their hands are untied. A psychotic of this exact type is revealed in a postrevolutionary situation. Here it is appropriate to recall the question Žižek often asks: What will there be the day after the revolution? There will be a hero who has conquered everyone and destroyed everything around them. They have destroyed destruction itself and remained in absolute solitude. What will be missing? In my view, a radical rethinking of the people will be missing, because the people will no longer be playing a major role in a postrevolutionary situation, and the psychotic will be experiencing a solitary state from which they cannot get out of. A governmental and moral universe arises in Hegel, but another turning can be imagined. The idea itself of the dictatorship of the proletariat introduces a proto-popular element into the revolution. This is what the innovation introduced by the Russian Revolution consists of, in comparison with the French Revolution as described by Hegel. 